\title{
Capacity precommitment and price competition yield the Cournot outcome
}

\author{
Diego Moreno ${ }^{\mathrm{a}, *}$, Luis Ubeda ${ }^{\mathrm{b}}$ \\ a Departamento de Economía, Universidad Carlos III de Madrid, 28903 Getafe, Spain \\ ${ }^{\mathrm{b}}$ Departamento de Fundamentos del Análisis Económico, Universidad de Alicante
}

Received 6 October 2004

Available online 1 December 2005

\begin{abstract}
We introduce a simple model of oligopolistic competition where firms first build capacity, and then, after observing the capacity decisions, choose a reservation price at which they are willing to supply their capacities. This model describes many markets more realistically than the model of Kreps and Scheinkman [Kreps, D., Scheinkman, J., 1983. Quantity precommitment and Bertrand competition yield Cournot outcomes. Bell J. Econ. 14, 326-337]. We show that in this new model every pure strategy equilibrium yields the Cournot outcome, and that the Cournot outcome can be sustained by a pure strategy subgame perfect equilibrium.
\end{abstract}

(c) 2005 Elsevier Inc. All rights reserved.

JEL classification: D43; L11; L13; L51

\section{Introduction}

We introduce a model of oligopolistic competition where firms first build capacity, and then, after observing the capacity decisions, choose a reservation price (a price per unit) at which they are willing to supply their entire capacities. The reservation price of each firm defines a sort of elementary supply. Firms' supplies are aggregated to form the market supply which, together

\footnotetext{
Financial support from the Comisión Nacional del Sistema Eléctrico and the Ministerio de Ciencia y Tecnología, grant SEJ2004-07861, is gratefully acknowledged. Ubeda acknowledges the financial support of the Instituto Valenciano de Investigaciones Económicas.

* Corresponding author. Fax: +34916249875.

E-mail address: diego.moreno@uc3m.es (D. Moreno).
} 
with the market demand, determines the output of each firm and the market clearing price. All firms sell their output at the market clearing price. We show that in this new model every pure strategy equilibrium yields the Cournot outcome, and that the Cournot outcome can be sustained by a pure strategy subgame perfect equilibrium.

In contrast, in Kreps and Scheinkman's (1983) model price competition is à la Bertrand. Under Bertrand competition each firm sets a price at which it offers to supply up to its capacity, and sells its output at this price, i.e., a firm's revenue per unit of output is the price it bids. The distinctive feature of the present model of price competition is that a firm does not set the final price at which it sells its output, but a reserve price at which it offers to supply up to its capacity. The price at which all firms sell their output is the market clearing price, i.e., a firm's revenue per unit of output is not the price it bids, but the market clearing price. (This feature is common to all models of competition via supply functions.)

This model of price competition describes many markets more closely than the Bertrand model: In financial markets, for example, where trade is centralized, most transactions occur at (or near) the market clearing price. Also in many of the recently deregulated utility industries that operate as organized markets firms sell their output at the market clearing price. In the Spanish market for electricity generation, for example, each firm submits a bid indicating the amount of output it wishes to sell and the minimum unit price it would accept; then a market operator aggregates firms' supplies and, using the market demand, determines the market clearing price and firms' outputs. (Specifically, in this market firms submit bids “... for each hourly scheduling period and production unit they own, with the expression of a price and an amount of power ... [for] as many as 25 power blocks ... with a different price for each of the said blocks, with the prices increasing from block to block."-Boletín Oficial del Estado, 20 May 2001, Regla 4.3. In our simple model each firm is assumed to have a single production unit, and bids are restricted to contain a single price and "power block.")

The analysis of the capacity constrained subgames of price competition of this new model leads to very different results from those obtained in Kreps and Scheinkman's model. Specifically, in this price competition game a pure strategy equilibrium always exists. In contrast, it is well known that in Kreps and Scheinkman's model for some capacity choices the unique equilibrium is in mixed strategies. In mixed strategy equilibria firms sometimes "regret" ex post their pricing decisions, which calls into question the validity of the equilibrium prediction since firms can easily change their prices-see Shapiro (1989) and Maggi (1996). In the context of complete information in which we set our model, pure strategy equilibria have the "no regret" property, and are therefore exempt from this critique.

It is also worth to note that for some capacity decisions there are multiple outcomes that can be sustained by pure strategy equilibria at the stage of price competition. Interestingly, when capacity is endogenized this multiplicity disappears, and only the Cournot outcome can be sustained by pure strategy equilibria. (Multiplicity of equilibria is pervasive in models of oligopolistic competition via supply functions when uncertainty is absent—see, e.g., Klemperer and Meyer, 1989. Remarkably, when the strategy sets in this model are restricted to contain only non-decreasing functions, Delgado and Moreno, 2004 also identify the Cournot outcome is the unique coalitionproof Nash equilibrium outcome.)

The argument establishing our main result, that every pure strategy equilibrium leads to the Cournot outcome, is relatively simple: in a pure strategy equilibrium at most one firm may have excess capacity, because if two firms have excess capacity, then one firm can undercut the other firm by using a reservation price slightly below the market clearing price. Assume, w.l.o.g., that firms 2 to $n$ are producing their full capacities, and suppose that Firm 1 has excess capacity. 
Consider the consequences of a deviation by Firm 1 to a capacity equal to its equilibrium output. Given that the capacities of firms 2 to $n$ are given, at the stage of price competition firms 2 to $n$ can produce at most their full capacities (i.e., firms 2 to $n$ cannot "retaliate"). But since these firms produce their full capacity along the equilibrium path, then the payoff of Firm 1 at the stage of price competition (revenue minus cost of production) does not decrease. Hence, since in our setting the cost of capacity is a strictly increasing function, this deviation would be profitable-Firm 1's revenue minus production cost does not decrease, whereas its cost of installing capacity decreases. Hence a situation where Firm 1 has excess capacity is not an equilibrium. Consequently, in a pure strategy equilibrium all firms produce at full capacity. Further, because all firms produce at full capacity, each firm's capacity must maximize its profits given the capacities (i.e., outputs) of the other firms; that is, in terms of capacity choices each firm must be on its "Cournot reaction function." Hence firms' capacities (and outputs) must form a Cournot equilibrium.

There are other interesting features of the model of price competition we introduce that are worth pointing out. Davidson and Deneckere (1986) have shown that the use of efficient rationing is crucial in Kreps and Scheinkman's result. In the present model, the profile of firms' reservation prices determines the aggregate supply and the market clearing price. Thus, no rationing rule is necessary. (Nevertheless, there is an implicit rationing in the way the market clearing price is determined.) And although a "tie-breaking rule" is needed to allocate demand when the reservation prices of two or more firms are equal to the market clearing price and there is not enough demand to absorb their capacities, our results hold regardless of the particular tie-breaking rule used.

When capacity decisions have no precommitment value our model yields results analogous to those obtained in Kreps and Scheinkman's model. In particular, when firms can build capacity instantaneously, the model reduces to Bertrand competition. When capacity is costless, a case we rule out, outcomes other than the Cournot outcome arise in equilibrium—see Osborne and Pitchik (1986). And when capacity is flexible—see Dixit (1980)—results similar to those obtained by Maggi (1996) in a version of the model with differentiated products can be readily extended to the model introduced in this paper-see also Vives (1986).

Other models of competition with endogenous capacity decisions have been previously introduced by Dixon (1985) and by Vives (1986). These models assume that firms choose strategically their capacities but behave as perfect competitors at the stage of price competition (i.e., each firm uses its marginal cost function as its supply schedule). In our framework, as in Kreps and Scheinkman's, firms behave strategically also at the price competition stage. Ubeda (2003) compares uniform price and discriminatory price auctions with exogenous and endogenous capacity constraints. Allen et al. (2000) have studied the issue of entry deterrence in a variation of Kreps and Scheinkman's model where capacity choices are sequential rather than simultaneous. Investigating how their results may be affected by the alternative mode of price competition that we study here is left for future research.

\section{The model}

The description of the industry, except for allowing more than two firms, is identical to that of Kreps and Scheinkman (1983). There are $n \geqslant 2$ firms in the industry. The market (inverse) demand function $P$ is twice continuously differentiable, strictly decreasing and concave on a bounded interval $(0, X)$, where $X>0$ satisfies $P(x)>0$ for $x<X$, and $P(x)=0$ for $x \geqslant X$. Write $D=P^{-1}$ for the market demand. All firms have access to the same technology. The cost to install capacity $x$ is $b(x)$, where $b: \mathbb{R}_{+} \rightarrow \mathbb{R}_{+}$is twice continuously differentiable and convex 
on $\mathbb{R}_{+}$, and satisfies $0<b^{\prime}(0)<P(0)$, and $b(0)=0$. The marginal cost of production up to capacity is constant, and without loss of generality it is assumed to be zero.

Competition runs in two stages: at the first stage firms choose their capacities. After the first stage firms observe their opponents' capacity decisions. At the second stage each firm chooses a "reservation price" (i.e., a unit price) at which to sell their entire capacities. Firms capacities and reservation prices are then used to form the aggregate supply which, together with the market demand, determines the market clearing price, $p$, and (using an unspecified tie-breaking rule) firms outputs, $\left(y_{1}, \ldots, y_{n}\right)$. Firm $i$ 's payoff is the difference between its revenue, $p y_{i}$, and its total cost, $b\left(x_{i}\right)$.

\section{Price competition with capacity constraints}

In this section we analyze the game firms face after they have made and observed their capacity decisions. Understanding these subgames is necessary to study the full game. In addition, since a distinguishing feature of our model is that it introduces an alternative form of price competition, the analysis of these games is of independent interest.

Let $x=\left(x_{1}, \ldots, x_{n}\right) \in \mathbb{R}_{+}^{n}$ be a profile of capacities, and denote by $\Gamma(x)$ the subgame firms face in the price competition stage. In this game, each firm $i \in N=\{1, \ldots, n\}$ chooses a reservation price $\rho_{i} \in \mathbb{R}_{+}$(i.e., a price per unit of output) at which it is willing to sell its entire capacity. A profile of reservation prices $\rho=\left(\rho_{1}, \ldots, \rho_{n}\right) \in \mathbb{R}_{+}^{n}$ determines the aggregate supply, $S(\rho ; \cdot)$, given for $p \in \mathbb{R}_{+}$by $S(\rho ; p)=\left[\sum_{j \in\left\{i \in N \mid \rho_{i}<p\right\}} x_{j}, \sum_{j \in\left\{i \in N \mid \rho_{i} \leqslant p\right\}} x_{j}\right]$, where $\sum_{j \in I} x_{j}=0$ if $I=\emptyset$. Note that when the price equals the reservation price of one or more firms, the value of aggregate supply is an interval. The market clearing price, $p(\rho)$, is uniquely determined by the market clearing condition $D(p) \in S(\rho ; p)$. Once the market clearing price is determined, the profile of outputs $y(\rho)=\left(y_{1}(\rho), \ldots, y_{n}(\rho)\right)$ can be readily calculated.

This is illustrated in Fig. 1 below. In Fig. 1(a), for example, the reservation price of Firm 1 is $\rho_{1}=0$, whereas that of Firm 2 is $\rho_{2}>0$; the supply schedule is therefore the thick step function; hence the market clearing price is $\rho_{2}$, and since $x_{1}<D\left(\rho_{2}\right)<x_{1}+x_{2}$, the output of Firm 1 is $y_{1}=x_{1}$, whereas the output of Firm 2 is $y_{2}=D\left(\rho_{2}\right)-x_{1}$. (In case of "ties," i.e., when the reservation price of several firms are equal to the market clearing price and the demand allocated to them is less than their capacities, a tie-breaking rule operates to determine the allocation of output. Our results do not depend on the particular tie-breaking rule used.) Firms' payoffs (profits) are given for $i \in N$ by $\pi_{i}(\rho)=p(\rho) y_{i}(\rho)-b\left(x_{i}\right)$. Note that at the stage of price competition capacity costs are sunk; hence in the game $\Gamma(x)$ firms maximize revenue.

We introduce some notation that will be useful in our analysis. For $c: \mathbb{R}_{+} \rightarrow \mathbb{R}_{+}$and $q \in \mathbb{R}_{+}$ let

$$
r_{c}(q)=\underset{s \in \mathbb{R}_{+}}{\arg \max } P(q+s) s-c(s),
$$

if $q<X$, and $r_{c}(q)=0$ if $q \geqslant X$; i.e., $r_{c}$ is the "reaction function" of a firm (when the strategic variable is output) calculated ignoring capacity constraints and assuming that the firm cost function is $c$. We write $r_{0}$ for a firm's reaction function calculated assuming that its marginal cost is zero. Our assumptions on $P$ guarantee that $r_{0}$ is well defined on $\mathbb{R}_{+}$, and satisfies $r_{0}(q)>0$, $q+r_{0}(q)<X$, and $P\left(q+r_{0}(q)\right) r_{0}(q)>0$ for all $q<X$. Likewise, we write $r_{b}$ for the reaction function of a firm calculated taking into account both the cost of capacity and the cost of production. Our assumptions on $P$ and on the cost of installing capacity $b$ guarantee that $r_{b}$ is well defined on $\mathbb{R}_{+}$. Note that $r_{0}(q)>r_{b}(q)$ for all $q<X$. 
For $i \in N$, write $x_{-i}=\sum_{j \in N \backslash\{i\}} x_{j}$, and

$$
I(x)=\left\{i \in N \mid x_{i}>r_{0}\left(x_{-i}\right)\right\} .
$$

The set $I(x)$ contains the indices of the firms that are not capacity constrained; i.e., whose capacities are above their Cournot reaction to their competitors capacities.

As we shall see, every game $\Gamma(x), x \in \mathbb{R}_{+}^{n}$, has a pure strategy equilibrium: If $I(x)=\emptyset$, i.e., if all firms are capacity constrained, then any profile of reservation prices $\rho \in\left[0, P\left(\sum_{j \in N} x_{j}\right)\right]^{n}$ is an equilibrium; further, in any pure strategy equilibrium all firms produce at full capacity and the market price is $P\left(\sum_{j \in N} x_{j}\right)$; hence, $\Gamma(x)$ has a unique pure strategy equilibrium outcome. If $I(x) \neq \emptyset$ and firms' capacities are so large that the residual demand of every firm is zero (i.e., if $x_{-i} \geqslant X$ for all $\left.i \in N\right)$, then $\rho=(0, \ldots, 0)$ is a pure strategy equilibrium of $\Gamma(x)$; further, in every pure strategy equilibrium the equilibrium price and firms' revenues are zero. If $I(x) \neq \emptyset$ and firms capacities are not too large (i.e., if $x_{-i}<X$ for some $i \in N$ ), then there is a pure strategy equilibrium with a simple structure: all but one firm set a low reservation price and produce at full capacity, and the remaining firm (the marginal firm) sets its reservation price in order to maximize its profits on the residual demand.

For $i, j \in N$, consider the inequality

$$
P\left(r_{0}\left(x_{-i}\right)+x_{-i}\right) x_{j} \geqslant P\left(r_{0}\left(x_{-j}\right)+x_{-j}\right) r_{0}\left(x_{-j}\right) .
$$

The right-hand side of $I C_{i j}$ is Firm $j$ 's revenue as the marginal firm, whereas the left-hand side is Firm $j$ 's revenue as an inframarginal firm when Firm $i$ is the marginal firm. Thus, when Firm $i$ is the marginal firm and the inequality above holds, Firm $j$ has no incentive to rise its reservation price above that of Firm $i$. Finally, define the set

$$
M(x)=\left\{i \in I(x) \mid I C_{i j} \text { holds for all } j \in I(x)\right\} .
$$

The set $M(x)$ contains the indices of the firms that may be "potential price setters"; that is, that may be marginal in equilibrium. The sets $I(x)$ and $M(x)$ will be useful to describe the pure strategy equilibria of $\Gamma(x)$.

In Fig. 1(a), Firm 1 produces at full capacity and Firm 2 maximizes on the residual demand, whereas in Fig. 1(b) the roles of the firms are interchanged. Of course, in order for the profile of reservation prices in Fig. 1(a) to be an equilibrium, the profits of Firm 1 (the inframarginal firm) must be greater than or equal to the profits it can get by raising its reservation price above that of Firm 2 and becoming the marginal firm, i.e., we must have $2 \in M(x)$. (In addition, the reservation price of Firm 2 must be sufficiently low that Firm 1 does not have an incentive to

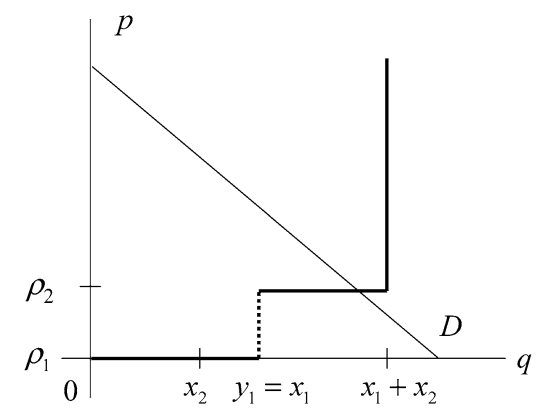

(a)

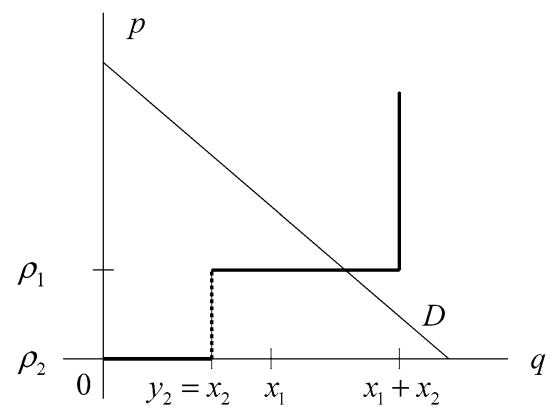

(b)

Fig. 1. Two pure strategy equilibria of a subgame of price competition. 


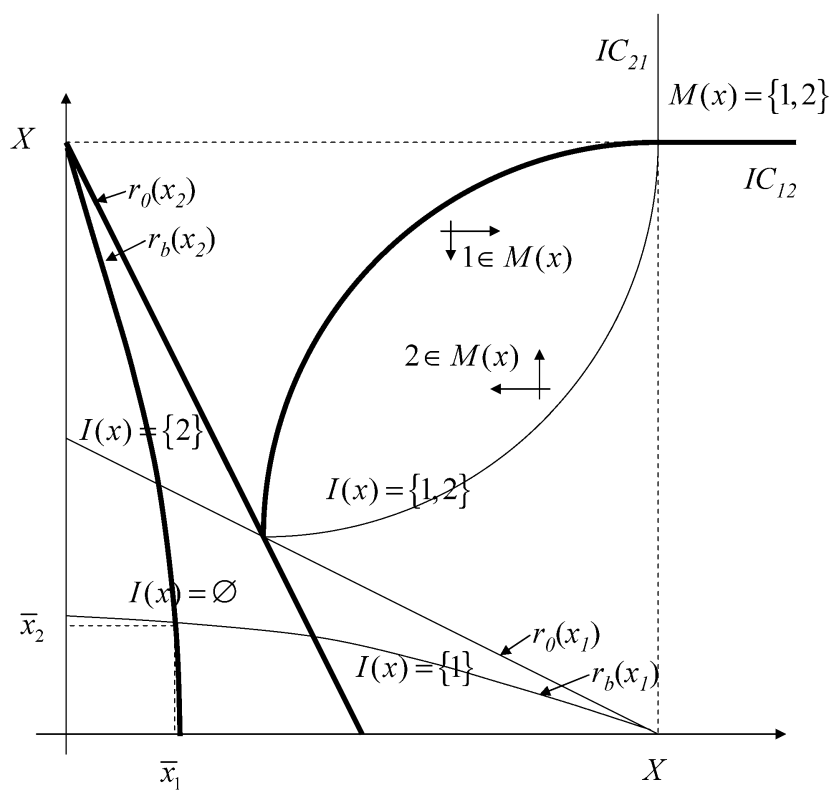

Fig. 2. Inside the "football" there are multiple equilibrium outcomes.

undercut Firm 2.) Likewise, for the situation in Fig. 1(b) to be an equilibrium we must have $1 \in M(x)$.

In Fig. 2, we have identified the sets $I(x)$ and $M(x)$ for a duopoly where the market demand is linear: The thick decreasing straight line is the function $r_{0}\left(x_{2}\right)$ (Firm 1's reaction function), whereas the thin decreasing straight line is the function $r_{0}\left(x_{1}\right)$ (Firm 2's reaction function). The thick curve starting at the intersection of the reaction functions (which merges with the horizontal line $x_{2}=X$ at the point $\left.(X, X)\right)$ is the locus of points $\left(x_{1}, x_{2}\right)>\left(r_{0}\left(x_{2}\right), r_{0}\left(x_{1}\right)\right)$ where $I C_{12}$ holds with equality. Likewise, the thin curve starting at the intersection of the reaction functions (which merges with the vertical line $x_{1}=X$ at the point $\left.(X, X)\right)$ is the locus of points $\left(x_{1}, x_{2}\right)>\left(r_{0}\left(x_{2}\right), r_{0}\left(x_{1}\right)\right)$ where $I C_{21}$ holds with equality. (Actually, both $I C_{21}$ and $I C_{21}$ hold with equality at every $\left(x_{1}, x_{2}\right) \geqslant(X, X)$; hence in this area the vertical and horizontal lines at $(X, X)$ are just the boundaries of the locus of points where $I C_{21}$ and $I C_{21}$ hold with equality.) Thus, above $r_{0}\left(x_{2}\right)$ (the thick straight line), Firm 1 is not capacity constrained, i.e., $1 \in I(x)$; in this region and below the thick curve, $I C_{12}$ holds, i.e., $1 \in M(x)$. Likewise, above $r_{0}\left(x_{1}\right)$ (the thin straight line), Firm 2 is not capacity constrained, i.e., $2 \in I(x)$; in this region and above the thin curve, $I C_{21}$ holds; i.e., $2 \in M(x)$.

The following lemma establishes some properties of the sets $I(x)$ and $M(x)$.

Lemma. Let $x \in \mathbb{R}_{+}^{n}$ be a vector of capacities.

(a) If $x_{j} \geqslant x_{i}$, then $r_{0}\left(x_{-i}\right)+x_{-i} \geqslant r_{0}\left(x_{-j}\right)+x_{-j}$, and $P\left(r_{0}\left(x_{-j}\right)+x_{-j}\right) \geqslant P\left(r_{0}\left(x_{-i}\right)+x_{-i}\right)$.

(b) If $i \in I(x)$ and $x_{j} \geqslant x_{i}$, then $j \in I(x)$.

(c) If $i \in M(x)$ and $x_{j} \geqslant x_{i}$, then $j \in M(x)$.

(d) If I $(x) \neq \emptyset$, then $M(x) \neq \emptyset$.

(e) Either $x_{-j} \geqslant X$ for all $j \in M(x)$, or $x_{-j}<X$ for all $j \in M(x)$.

(f) If $x_{-i} \geqslant X$ for some $i \in M(x)$, then $x_{-j} \geqslant X$ for all $j \in N$. 
Proof. Let $x \in \mathbb{R}_{+}^{n}$ be a vector of capacities. We prove Lemma (a). Let $x_{j} \geqslant x_{i}$. Then

$$
x_{-i}=x_{-j}+\left(x_{j}-x_{i}\right) \geqslant x_{-j} .
$$

Since $r_{0}(q)+q$ is nondecreasing in $q$ - see Kreps and Scheinkman (1983, Lemma 1(b))—we have

$$
r_{0}\left(x_{-i}\right)+x_{-i} \geqslant r_{0}\left(x_{-j}\right)+x_{-j} .
$$

And because $P(q)$ is decreasing in $q$, we have

$$
P\left(r_{0}\left(x_{-j}\right)+x_{-j}\right) \geqslant P\left(r_{0}\left(x_{-i}\right)+x_{-i}\right) .
$$

We prove Lemma (b). Let $i \in I(x)$ and $x_{j} \geqslant x_{i}$. By Lemma (a),

$$
r_{0}\left(x_{-i}\right)+x_{-i}=r_{0}\left(x_{-i}\right)+x_{-j}+\left(x_{j}-x_{i}\right) \geqslant r_{0}\left(x_{-j}\right)+x_{-j} .
$$

Hence, since $x_{i}>r_{0}\left(x_{-i}\right)$ (because $\left.i \in I(x)\right)$, we have

$$
0>r_{0}\left(x_{-i}\right)-x_{i} \geqslant r_{0}\left(x_{-j}\right)-x_{j} .
$$

Therefore $x_{j}>r_{0}\left(x_{-j}\right)$, and $j \in I(x)$.

We prove Lemma (c). Assume that $i \in M(x)$ and $x_{j} \geqslant x_{i}$. Then $j \in I(x)$ by Lemma (b), and $P\left(r_{0}\left(x_{-j}\right)+x_{-j}\right) \geqslant P\left(r_{0}\left(x_{-i}\right)+x_{-i}\right)$ by Lemma (a). Thus, since $i \in M(x)$, for $k \in I(x)$ we have

$$
P\left(r_{0}\left(x_{-j}\right)+x_{-j}\right) x_{k} \geqslant P\left(r_{0}\left(x_{-i}\right)+x_{-i}\right) x_{k} \geqslant P\left(r_{0}\left(x_{-k}\right)+x_{-k}\right) r_{0}\left(x_{-k}\right) .
$$

Hence $j \in M(x)$.

We prove Lemma (d). Assume that $I(x) \neq \emptyset$; let $j \in I(x)$ be such that $x_{j}=\max _{k \in I(x)} x_{k}$, and let $i \in I(x)$ arbitrary. Since $x_{j} \geqslant x_{i}$ and $x_{i}>r_{0}\left(x_{-i}\right)$, Lemma (a) implies

$$
P\left(r_{0}\left(x_{-j}\right)+x_{-j}\right) x_{i} \geqslant P\left(r_{0}\left(x_{-i}\right)+x_{-i}\right) r_{0}\left(x_{-i}\right) .
$$

Hence $j \in M(x)$.

We prove Lemma (e). Assume that there is $i \in M(x)$ such that $x_{-i} \geqslant X$, and let $j \in M(x)$ arbitrary. We show that $x_{-j} \geqslant X$, which establishes the lemma. Since $x_{-i} \geqslant X$, we have $P\left(r_{0}\left(x_{-i}\right)+x_{-i}\right)=0$. Hence $i \in M(x)$ and $j \in M(x) \subset I(x)$ imply

$$
0=P\left(r_{0}\left(x_{-i}\right)+x_{-i}\right) x_{j} \geqslant P\left(r_{0}\left(x_{-j}\right)+x_{-j}\right) r_{0}\left(x_{-j}\right) .
$$

Thus, since $r_{0}(q) \geqslant 0$ for all $q$, and $P(q)=0$ for $q \geqslant X$, we have $P\left(r_{0}\left(x_{-j}\right)+x_{-j}\right) r_{0}\left(x_{-j}\right)=0$. Therefore $x_{-j} \geqslant X$.

Finally, we prove Lemma (f). Assume that there is $i \in M(x)$ such that $x_{-i} \geqslant X$. Then $x_{-j} \geqslant X$ for all $j \in M(x)$ by Lemma (e). Further, for each firm $j \in N \backslash M(x)$, we have $x_{j}<x_{i}$ by Lemma (c), and therefore

$$
x_{-j}=x_{-i}+\left(x_{i}-x_{j}\right)>x_{-i} \geqslant X .
$$

Figures 1(a) and 1(b) suggest the possibility that multiple pure strategy equilibrium outcomes may emerge. For this to occur several combinations of marginal and inframarginal firms must be possible. As we shall see in Proposition A, this requires that the set $M(x)$ contain two or more indices, and that firms' capacities not be too large. For a duopoly with a linear demand as that described in Fig. 2, multiplicity arises when the profile of capacities is in the area inside the "football."

We establish these results formally in Proposition A. 
Proposition A. Let $x \in \mathbb{R}_{+}^{n}$ be a vector of capacities. The game $\Gamma(x)$ has a pure strategy equilibrium. Moreover, if $\# M(x)>1$ and $x_{-i}<X$ for some $i \in N$, then there are multiple outcomes that can be sustained by pure strategy equilibria.

Proof. Let $x \in \mathbb{R}_{+}^{n}$ be a vector of capacities. First we show that $\Gamma(x)$ has a pure strategy equilibrium.

Assume that $I(x)=\emptyset$. Hence $r_{0}\left(x_{-j}\right) \geqslant x_{j}$ for all $j \in N$. Let $\rho \in\left[0, P\left(\sum_{j \in N} x_{j}\right)\right]^{n}$. Then $p(\rho)=P\left(\sum_{j \in N} x_{j}\right)$, and $y_{j}(\rho)=x_{j}$ for $j \in N$. We show that $\rho$ is an equilibrium of $\Gamma(x)$. Let $i \in N$. Since for each profile of reservation prices each firm $j \in N$ produces $y_{j} \leqslant x_{j}$, and since $r_{0}(q)$ is nonincreasing in $q$-see Kreps and Scheinkman (1983, Lemma 1(a)) - then $r_{0}\left(y_{-i}\right) \geqslant$ $r_{0}\left(x_{-i}\right) \geqslant x_{i}$. Hence profit maximization requires that Firm $i$ produces its full capacity; i.e., $y_{i}=x_{i}$. Now, since $\rho_{j} \leqslant p(\rho)$ for $j \in N \backslash\{i\}$, any reservation price $\rho_{i}^{\prime} \neq \rho_{i}$ such that $\rho_{i}^{\prime}>p(\rho)$ leads to an output for Firm $i$ less than $x_{i}$ and is therefore suboptimal. Moreover, any reservation price $\rho_{i}^{\prime} \neq \rho_{i}$ such that $\rho_{i}^{\prime} \leqslant p(\rho)=P\left(\sum_{j \in N} x_{j}\right)$ neither changes the market clearing price nor Firm $i$ 's output. Thus, $\rho_{i}$ is optimal, and therefore $\rho$ is equilibrium.

Assume that $I(x) \neq \emptyset$; then $M(x) \neq \emptyset$ by Lemma (d). Let $i \in M(x)$, and let the profile of reservation prices $\rho$ be given by $\rho_{i}=P\left(r_{0}\left(x_{-i}\right)+x_{-i}\right)$ and $\rho_{j}=0$ for $j \in N \backslash\{i\}$. We show that $\rho$ is an equilibrium.

If $x_{-i} \geqslant X$, then $p(\rho)=\rho_{i}=0$. Hence firms' revenues are zero. Now, $i \in M(x)$ and $x_{-i} \geqslant X$ imply $x_{-j} \geqslant X$ for all $j \in N$ by Lemma (f); i.e., the residual demand of every firm is zero. Further given that $\rho_{i}=0$ for all $i \in N$, the revenue that a firm $j \in N$ may obtain by deviating to a reservation price $\rho_{j}^{\prime}$ is bounded above by $P\left(r_{0}\left(x_{-j}\right)+x_{-j}\right) r_{0}\left(x_{-j}\right)=0$. Hence $\rho$ is an equilibrium.

If $x_{-i}<X$, then $p(\rho)=\rho_{i}=P\left(r_{0}\left(x_{-i}\right)+x_{-i}\right)>0, y_{i}(\rho)=r_{0}\left(x_{-i}\right)$, and $y_{j}(\rho)=x_{j}$ for $j \in N \backslash\{i\}$. Since Firm $i$ cannot undercut any other firm, and $y_{i}(\rho)=r_{0}\left(x_{-i}\right)$ maximizes its profits on its residual demand by construction, it cannot profitably deviate. Now, a deviation by a Firm $j \in N \backslash\{i\}$ to a reservation price $\rho_{j}^{\prime}<\rho_{i}$ does not change the outcome (see Fig. 1). Consider a deviation to $\rho_{j}^{\prime}>\rho_{i}$ by a firm $j \in N \backslash\{i\}$. If $j \in I(x)$, such deviation generates a revenue no greater than $P\left(r_{0}\left(x_{-j}\right)+x_{-j}\right) r_{0}\left(x_{-j}\right)$, and $i \in M(x)$ implies

$$
P\left(r_{0}\left(x_{-j}\right)+x_{-j}\right) r_{0}\left(x_{-j}\right) \leqslant P\left(r_{0}\left(x_{-i}\right)+x_{-i}\right) x_{j}=\rho_{i} x_{j}=p(\rho) y_{j}(\rho) ;
$$

hence $\rho_{j}^{\prime}$ is not a profitable deviation. If $j \in N \backslash I(x)$, then $x_{j} \leqslant r_{0}\left(x_{-j}\right)$ (i.e., Firm $j$ is capacity constrained), and therefore the deviation generates a revenue no greater than $P\left(x_{j}+x_{-j}\right) x_{j}$; but

$$
x_{j}+x_{-j}=x_{i}+x_{-i}>r_{0}\left(x_{-i}\right)+x_{-i},
$$

and therefore since $P$ is decreasing,

$$
P\left(x_{j}+x_{-j}\right) x_{j}<P\left(r_{0}\left(x_{-i}\right)+x_{-i}\right) x_{j}=\rho_{i} x_{j}=p(\rho) y_{j}(\rho)
$$

hence $\rho_{j}^{\prime}$ is not a profitable deviation either. Finally, a deviation to $\rho_{j}^{\prime}=\rho_{i}$ leads to a revenue that (depending on the tie breaking rule) is at most $\rho_{i} x_{j}$, and therefore it is not a strictly profitable deviation.

Hence $\rho$ is an equilibrium, and therefore $\Gamma(x)$ has a pure strategy equilibrium.

Finally, we establish the existence multiple outcomes that can be sustained by pure strategy equilibria whenever $\# M(x)>1$ and $x_{-i}<X$ for some $i \in N$. Note that these conditions imply that $x_{-j}<X$ for all $j \in M(x)$ by Lemma (f). Then take $j, j^{\prime} \in M(x)$, and let the profiles $\rho$ and $\rho^{\prime}$ be given by $\rho_{j}=P\left(r_{0}\left(x_{-j}\right)+x_{-j}\right)>0$ and $\rho_{k}=0$ for $k \in N \backslash\{j\}$, and by $\rho_{j^{\prime}}^{\prime}=P\left(r_{0}\left(x_{-j^{\prime}}\right)+\right.$ $\left.x_{-j^{\prime}}\right)>0$ and $\rho_{k}^{\prime}=0$ for $k \in N \backslash\left\{j^{\prime}\right\}$. As shown above both $\rho$ and $\rho^{\prime}$ are pure strategy equilibria 
of $\Gamma(x)$. Further $y_{j}(\rho)=r_{0}\left(x_{-j}\right)<x_{j}=y_{j}\left(\rho^{\prime}\right)$, so that these two pure strategy equilibria lead to different outcomes. (Note also that if $x_{i} \neq x_{j}$ then $p(\rho) \neq p\left(\rho^{\prime}\right)$.)

\section{Equilibria in the full game}

Interestingly, the multiplicity that arises at the stage of price competition disappears when capacity is endogenized. As established in Theorem B below only the Cournot outcome (of the industry where firms' costs are the sum of the costs of capacity and production) can be sustained by pure strategy equilibria of the full game.

Theorem B. Every pure strategy equilibrium yields the Cournot outcome. Moreover, the Cournot outcome can be sustained by a subgame perfect equilibrium in pure strategies.

Proof. Denote by $\bar{x}$ and $\bar{y}$ the vectors of capacity choices and outputs at an arbitrary pure strategy equilibrium of the full game, and let $\bar{p}$ be the resulting market clearing price. Clearly $\bar{x}_{i}>0$ for some $i \in N$, for if $\bar{x}_{i}=0$ for every $i \in N$, since $b^{\prime}(0)<P(0)$ by assumption, then a firm benefits by installing a small but positive capacity. And since our assumptions on cost imply that a firm obtains zero profits by installing no capacity, we must have $\bar{p} \bar{y}_{i} \geqslant b\left(\bar{x}_{i}\right)$. Hence $\bar{x}_{i}>0$ for some $i \in N$, implies $b\left(\bar{x}_{i}\right)>0$ (note that $b$ is convex and satisfies $b^{\prime}(0)>0$, and therefore is strictly increasing), and therefore $\bar{y}_{i}>0$ and $\bar{p}>0$. Further, it is easy to show that all but at most one firm must produce at full capacity: If firms $i$ and $j$ produce less than their capacities, then $\rho_{i}=$ $\rho_{j}=\bar{p}>0$, and therefore either firm can undercut the other firm by choosing a reservation price slightly below the market clearing price, and increase its profit. Assume, w.l.o.g., that firms 2 to $n$ are producing at full capacity; i.e., $\bar{y}_{i}=\bar{x}_{i}$ for $i \in N \backslash\{1\}$. Recall that $r_{b}$ is the Cournot reaction function calculated taking into account both the cost of capacity and the cost of production. We show that $\bar{x}_{1}=r_{b}\left(\bar{x}_{-1}\right)=\bar{y}_{1}$.

First we show that $\bar{x}_{1}=\bar{y}_{1}$. Suppose that $\bar{x}_{1}>\bar{y}_{1}$; since $\bar{p}>0$, we must have $\bar{x}_{-1}<X$. Also $\bar{y}_{i}=\bar{x}_{i}$ implies $\rho_{i} \leqslant \rho_{1}$ for $i \in N \backslash\{1\}$. Profit maximization therefore requires that the output of Firm $1, \bar{y}_{1}$, maximizes its profits on the residual demand $D(p)-\bar{x}_{-1}$. Consider a deviation by Firm 1 that reduces its capacity to $x_{1}=\bar{y}_{1}$. This deviation induces a new game of price competition $\Gamma\left(x_{1}, \bar{x}_{2}, \ldots, \bar{x}_{n}\right)$. In this game, the residual demand of Firm 1 is, whatever the strategies of firms 2 to $n$, at least $X-\bar{x}_{-1}$. Therefore Firm 1 can guarantee itself a revenue of at least $\bar{p} \bar{y}_{1}$. Hence the revenue of Firm $i$ does not decrease, whereas the cost of installing capacity $x_{1}<\bar{x}_{1}$ decreases (because $b$ is strictly increasing). Since such a profitable deviation cannot exist, we must have $\bar{x}_{1}=\bar{y}_{1}$.

Now, because Firm 1's residual demand is at least $X-\bar{x}_{-1}$, we must have $\bar{y}_{1} \geqslant r_{b}\left(\bar{x}_{-1}\right)$, for otherwise Firm 1 can increase its profit by increasing its capacity and output. Moreover, producing $\bar{y}_{1}>r_{b}\left(\bar{x}_{-1}\right)$ is suboptimal: a deviation to $\bar{x}_{1}=\bar{y}_{1}=r_{b}\left(\bar{x}_{-1}\right)$ would increase Firm 1's profits (whatever the reaction of firms 2 to $n$ may be in the game of price competition). Hence $\bar{x}_{1}=\bar{y}_{1}=r_{b}\left(\bar{x}_{-1}\right)$.

Further, since Firm 1 is also producing at full capacity, the previous argument applies to firms 2 to $n$ as well; i.e., $\bar{x}_{i}=\bar{y}_{i}=r_{b}\left(\bar{x}_{-i}\right)$ for $i \in\{2, \ldots, n\}$. Hence $\bar{x}=\bar{y}$ form a Cournot equilibrium of the industry where firms' costs are the sum of the costs of capacity and production.

Now, it is easy to construct a pure strategy subgame perfect equilibrium of the full game that sustains the Cournot equilibrium of the industry where firms' costs are the sum of the costs of capacity and production, $\bar{x}$. Consider the strategy profile $(\bar{x}, f)$, where $f: \mathbb{R}_{+}^{n} \rightarrow \mathbb{R}_{+}^{n}$, the profile of reservation prices used by firms for each $x \in \mathbb{R}_{+}^{n}$, is defined as follows: let $x \in \mathbb{R}_{+}^{n}$. if $I(x)=\emptyset$, 
then let $f(x) \in\left[0, P\left(\sum_{j \in N} x_{j}\right)\right]^{n}$ arbitrary; if $I(x) \neq \emptyset$, then let $f_{i}(x)=P\left(r_{0}\left(x_{-i}\right)+x_{-i}\right)$ and $f_{j}(x)=0$ for $j \in N \backslash\{i\}$, where $i \in N$ is the smallest index in $M(x)$ such that $x_{i}=\max _{j \in M(x)} x_{j}$. Since $\bar{x}_{j}=r_{b}\left(\bar{x}_{-j}\right)<r_{0}\left(\bar{x}_{-j}\right)$ for all $j \in N$, we have $I(\bar{x})=\emptyset$. Therefore $(\bar{x}, f)$ leads to the outcome $p(\bar{x}, f)=P\left(\sum_{j \in N} \bar{x}_{j}\right)$, and $y_{j}(\bar{x}, f)=\bar{x}_{j}$ for all $j \in N$.

We show that $(\bar{x}, f)$ is a subgame perfect equilibrium. As established in the proof of Proposition A, for each $x \in \mathbb{R}_{+}^{n}, f(x)$ is a pure strategy equilibrium of $\Gamma(x)$. Hence a firm cannot profitably deviate after it has made its capacity choice. Further, since all firms are capacity constrained, the argument above shows each firm $i \in N$ must set its capacity equal to $r_{b}\left(\bar{x}_{-i}\right)$. Hence $(\bar{x}, f)$ is a subgame perfect equilibrium.

\section{Acknowledgments}

We are grateful to an anonymous referee for many detailed comments and suggestions.

\section{References}

Allen, B., Deneckere, R., Faith, T., Kovenock, D., 2000. Capacity precommitment as a barrier to entry: A BertrandEdgeworth approach. Econ. Theory 15, 501-530.

Boletín Oficial del Estado, 20 May 2001. Reglas del mercado de producción de energía eléctrica, Regla 4.3. Spain. English translation: http://www.comel.es/frames/en/index_eng.jsp.

Davidson, C., Deneckere, R., 1986. Long-run competition in capacity, short-run competition in price and Cournot model. RAND J. Econ. 17, 404-415.

Delgado, J., Moreno, D., 2004. Coalition-proof supply function equilibria in oligopoly. J. Econ. Theory 114, $231-254$.

Dixit, A., 1980. The role of investment in entry deterrence. Econ. J. 90, 95-106.

Dixon, H., 1985. Strategic investment in an industry with a competitive product market. J. Ind. Econ. 33, 483-499.

Klemperer, P., Meyer, M., 1989. Supply function equilibria in oligopoly under uncertainty. Econometrica 57, $1243-1277$.

Kreps, D., Scheinkman, J., 1983. Quantity precommitment and Bertrand competition yield Cournot outcomes. Bell J. Econ. 14, 326-337.

Maggi, G., 1996. Strategic trade policies with endogenous mode of competition. Amer. Econ. Rev. 86, $237-258$.

Osborne, M., Pitchik, C., 1986. Price competition in a capacity-constrained duopoly. J. Econ. Theory 38, 238-260.

Shapiro, C., 1989. Theories of oligopoly behavior. Chapter 6 in: Schmalensee, R., Willig, R.D. (Eds.), Handbook of Industrial Organization, vol. 1. North-Holland, Amsterdam, pp. 329-410.

Ubeda L., 2003. Capacity and market design: Discriminatory versus uniform price auctions. Manuscript.

Vives, X., 1986. Commitment, flexibility and market outcomes. Int. J. Ind. Organ. 4, 217-229. 